\title{
Electronic vs. Steric Hindrance Effects in Amine Ligands to Ru-Based Initiators for ROMP
}

\author{
Tiago B. Silva, Ricardo S. Camargo and Benedito S. Lima-Neto* \\ Instituto de Química de São Carlos, Universidade de São Paulo (USP), \\ CP 780, 13560-970 São Carlos-SP, Brazil
}

\begin{abstract}
Complexos do tipo $\left[\mathrm{RuCl}_{2}\left(\mathrm{PPh}_{3}\right)_{2}(\text { amina })_{\mathrm{x}}\right], \operatorname{com~NH}_{2} \mathrm{Ph}(\mathbf{1} ; \mathrm{x}=2), \mathrm{NH}_{2} \mathrm{Bz}(\mathbf{2} ; \mathrm{x}=2)$ and $\mathrm{NHBuPh}$ $(\mathbf{3} ; \mathrm{x}=1)$ na presença de etildiazoacetato (EDA), foram aplicados em reações de polimerização via metátese por abertura de anel (ROMP) de norborneno (NBE), norbornadieno (NBD) e diciclopentadieno (DCPD). Rendimentos quantitativos de poliNBE foram obtidos a $50{ }^{\circ} \mathrm{C}$ por $30 \mathrm{~min}$ usando 1 e por 5 min usando 2 . Isso ocorreu a $25{ }^{\circ} \mathrm{C}$ por 5 min quando foi usado 3 . Os valores do índice de polidispersidade (PDI) variaram de 3,5 a $1,6\left(M_{\mathrm{w}}=10^{4}-10^{5} \mathrm{~g} \mathrm{~mol}^{-1}\right)$. O complexo 3 foi ativo para ROMP de NBD e DCPD, bem como para copolimerização de NBE com NBD ou com DCPD. $\mathrm{O}$ maior caráter $\sigma$-doador de $\mathrm{NH}_{2} \mathrm{Bz}$ em $\mathbf{2}$, em relação a $\mathrm{NH}_{2} \mathrm{Ph}$ em $\mathbf{1}$, favoreceu a reatividade do complexo 2 que é hexacoordenado como 1. O ângulo de cone de NHBuPh definiu a pentacoordenação em 3 e a sua melhor reatividade para ROMP, apesar do baixo caráter $\sigma$-doador como o de $\mathrm{NH}_{2} \mathrm{Ph}$.
\end{abstract}

$\left[\mathrm{RuCl}_{2}\left(\mathrm{PPh}_{3}\right)_{2}(\text { amine })_{\mathrm{x}}\right]$-type complexes, with $\mathrm{NH}_{2} \mathrm{Ph}(\mathbf{1} ; \mathrm{x}=2), \mathrm{NH}_{2} \mathrm{Bz}(\mathbf{2} ; \mathrm{x}=2)$ and $\mathrm{NHBuPh}$ $(3 ; \mathrm{x}=1)$ in the presence of ethyldiazoacetate (EDA), were investigated for ring opening metathesis polymerization (ROMP) of norbornene (NBE), norbornadiene (NBD) and dicyclopentadiene (DCPD). Quantitative yields of polyNBE were obtained at $50^{\circ} \mathrm{C}$ for $30 \mathrm{~min}$ with 1 and for $5 \mathrm{~min}$ with $\mathbf{2}$, whereas this occurred at $25^{\circ} \mathrm{C}$ for 5 min with 3 . Polydispersity index (PDI) values ranged from 3.5 to $1.6\left(M_{\mathrm{w}}=\right.$ $10^{4}-10^{5} \mathrm{~g} \mathrm{~mol}^{-1}$ ). Complex 3 was active for ROMP of NBD and DCPD, as well as for copolymerizations of NBE with either NBD or DCPD. The high $\sigma$-donor character of $\mathrm{NH}_{2} \mathrm{Bz}$ favored the reactivity of the six-coordinated complex $\mathbf{2}$, contrary to complex $\mathbf{1}$. The large cone angle of $\mathrm{NHBuPh}$ defined the fivecoordination in $\mathbf{3}$ and the best reactivity for ROMP, in spite of the low $\sigma$-donor character as in $\mathrm{NH}_{2} \mathrm{Ph}$.

Keywords: ancillary ligands, amines, ruthenium, olefin metathesis, ROMP

\section{Introduction}

Cycloalkenes undergo ring-opening metathesis polymerization (ROMP) catalyzed by a transition metalcarbene complex to result in a polymer with the carboncarbon double bond retained. ${ }^{1-5}$ ROMP is also a practical method to produce copolymers and can be combined either with different olefin metathesis $(\mathrm{OM})$ procedures or other polymerization methods. ${ }^{6-9}$

A diversity of catalysts have been tested from complexes of $\mathrm{Ru}, \mathrm{W}, \mathrm{Mo}, \mathrm{Ti}, \mathrm{Ta}, \mathrm{Nb}, \mathrm{V}, \mathrm{Re}, \mathrm{Ni}$, etc. ${ }^{1,10-15}$ Besides the electronic nature of the metal center to select an olefin instead of an oxo-compound in the medium, ${ }^{16}$ the success of ROMP is strongly influenced by ancillary ligands. ${ }^{17,18}$ These ligands directly influence the reaction mechanism via an intramolecular interaction between a coordinated olefin

*e-mail: benedito@iqsc.usp.br and a metal-carbene moiety to produce a metallocyclobutane intermediate. ${ }^{1,2}$ The correct geometric arrangement to permit the orbital overlap and the electronic activation are determinant for OM success. ${ }^{19}$ Thus, the advance in ROMP is associated with the design of new catalysts, considering the behavior of the ancillary ligands in the metal coordination sphere to improve stability, reactivity, selectivity, solubility or latency toward the addressed polymers. ${ }^{17,20-24}$

Usually, the ancillary ligands in OM with Ru-based complex are bulky and good $\sigma$-donors. ${ }^{20}$ The steric hindrance comes from the cone angle $(\theta)$, as defined by Tolman. ${ }^{25}$ The $\sigma$-donor ability is rationalized in terms of $\mathrm{pK}_{\mathrm{a}}$ value of the molecule. ${ }^{26}$

We have worked in the development of the $\left[\mathrm{RuCl}_{2}(\text { phosphine })_{\mathrm{x}}(\text { amine })_{\mathrm{y}}\right]$-type complex for ROMP and copolymerization (ROMCP) with the idea of combining phosphine and amine to obtain helpful electronic and steric effects for the occurrence of reactions. A long list of amines 
has been attained for this proposal, ${ }^{27-31}$ with significant changes in the polymer characteristic, such as molecular weight, polydispersity index (PDI), thermal properties, morphological shape, etc. ${ }^{27-31}$

In the present study, we focus on the development of Rubased catalysts combining the phosphine $\mathrm{PPh}_{3}$ with amines of the type $\mathrm{NHR}_{1} \mathrm{R}_{2}$ to act as ancillary ligands, where the amine substituents $R_{1}$ and $R_{2}$ permute their characteristics considering the electronic nature and steric hindrance. The amines phenylamine $\left(\mathrm{NH}_{2} \mathrm{Ph}\right.$; aniline) and benzylamine $\left(\mathrm{NH}_{2} \mathrm{Bz}\right.$ ) present $\mathrm{R}_{1}=\mathrm{H}$ and different $\mathrm{R}_{2}$ groups ( $\mathrm{Ph}$ or $\mathrm{Bz}$ ), where the $\mathrm{CH}_{2}$ unit between the $\mathrm{N}$ and the $\mathrm{Ph}$ ring in $\mathrm{NH}_{2} \mathrm{Bz}$ promotes an increase in the $\sigma$-donor nature as evaluated from the $\mathrm{pK}_{\mathrm{a}}$ values (Figure 1), without significantly changing the cone angles $(\theta)$. On the other hand, changing $R_{1}=H$ for the ${ }^{n} \mathrm{Bu}$ chain in $\mathrm{NH}_{2} \mathrm{Ph}$ results in the amine $N-{ }^{n}$ butylphenylamine (NHBuPh; $N-{ }^{n}$ Butylaniline), which presents similar $\sigma$-donor nature to $R_{1}=H$ (Figure 1), but a larger cone angle in $\mathrm{NHBuPh}$ is expected. The main purpose of this study is to analyze the more appropriate characteristics ( $\sigma$-donor and $\theta$ ) of the amines to combine with $\mathrm{PPh}_{3}$ in Ru-based-type complex for ROMP and ROMCP of norbornene (NBE), norbornadiene (NBD) and dicyclopentadiene (DCPD). The use of $\mathrm{PPh}_{3}$ is appropriate to avoid easy oxidation of the $\mathrm{Ru}$ (II) metal center (a low spin $\mathrm{d}^{6}$ configuration) and be helpful with the steric hindrance. In addition, $\mathrm{PPh}_{3}$ is air-stable in the solid state and cheap. The current amines are non- $\pi$-receptor molecules and they act only as $\sigma$-donor ligands to promote olefin activation via metathesis.

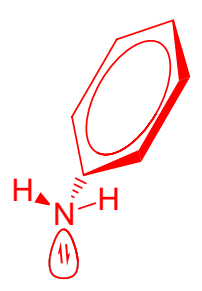

Phenylamine $\left(\mathrm{NH}_{2} \mathrm{Ph}\right)$ $\mathrm{pK}_{\mathrm{a}}=4.70$ $\theta=111^{\circ}$

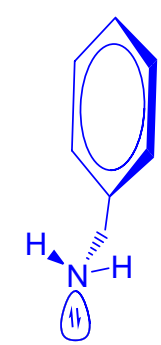

Benzylamine $\left(\mathrm{NH}_{2} \mathrm{Bz}\right)$ $\mathrm{pK}_{\mathrm{a}}=9.40$ $\theta=106^{\circ}$

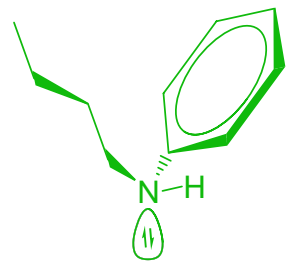

$N-{ }^{n}$ Butylphenylamine (NHBuPh) $\mathrm{pK}_{\mathrm{a}}=4.95$ $\theta>\theta_{\text {NHEtPh }}\left(126^{\circ}\right)$
Figure 1. Chemical structures of the amines $\mathrm{NHR}_{1} \mathrm{R}_{2}$.

\section{Experimental}

\section{General remarks}

All manipulations were performed under argon atmosphere. High-performance liquid chromatography (HPLC)-grade $\mathrm{CHCl}_{3}$ was used as received. Other solvents were of analytical grade and were distilled from the appropriate drying agents prior to use. Other commercially available reagents were used without further purification. $\mathrm{RuCl}_{3} \cdot x \mathrm{H}_{2} \mathrm{O}$, norbornene (NBE), norbornadiene (NBD), dicyclopentadiene (DCPD), ethyl diazoacetate (EDA; contains $\geq 13$ wt. $\left.\% \mathrm{CH}_{2} \mathrm{Cl}_{2}\right)$, phenylamine $\left(\mathrm{NH}_{2} \mathrm{Ph}\right)$, benzylamine $\left(\mathrm{NH}_{2} \mathrm{Bz}\right)$ and $\mathrm{N}^{-}{ }^{n}$ butylphenylamine $(\mathrm{NHBuPh})$ were used as acquired from Aldrich. The $\left[\mathrm{RuCl}_{2}\left(\mathrm{PPh}_{3}\right)_{3}\right]$ complex was prepared following the literature and its purity was verified by satisfactory elemental analysis and spectroscopic examination $\left({ }^{31} \mathrm{P}\left\{{ }^{1} \mathrm{H}\right\}\right.$ and ${ }^{1} \mathrm{H}$ nuclear magnetic resonance (NMR); Fourier transform infrared (FTIR)). ${ }^{32}$ Room temperature (RT) was $24 \pm 1{ }^{\circ} \mathrm{C}$.

\section{Synthesis of $\left[\mathrm{RuCl}_{2}\left(\mathrm{PPh}_{3}\right)_{2}\left(\mathrm{NH}_{2} \mathrm{Ph}\right)_{2}\right](1)$}

This complex was obtained following the literature with few changes. ${ }^{28}\left[\mathrm{RuCl}_{2}\left(\mathrm{PPh}_{3}\right)_{3}\right](0.52 \mathrm{mmol} ; 0.50 \mathrm{~g})$ was added to a solution of $\mathrm{NH}_{2} \mathrm{Ph}(10.4 \mathrm{mmol} ; 0.97 \mathrm{~g})$ in acetone $(30 \mathrm{~mL})$. The solution became green for $5 \mathrm{~min}$ and changed to purple for $12 \mathrm{~h}$ under stirring at RT. The volume was reduced to ca. $5 \mathrm{~mL}$ under flow of argon at RT. Cold $n$-hexane was added and a purple compound precipitated, which was filtered, washed with ethyl ether and dried in vacuum. Yield: $60 \%$; calcd. anal. data for $\mathrm{RuCl}_{2} \mathrm{P}_{2} \mathrm{C}_{48} \mathrm{H}_{44} \mathrm{~N}_{2}$ : 65.2 C, 5.1 H, 3.2\% N; found: 64.6 C, $5.2 \mathrm{H}, 3.2 \% \mathrm{~N}$; IR (CsI) $v_{\text {max }} / \mathrm{cm}^{-1} 3286(\mathrm{~s}, \mathrm{~N}-\mathrm{H}), 1090$ (s, $\mathrm{P}-\mathrm{C}$ ), and 287 (s, Ru-Cl); ${ }^{31} \mathrm{P}$ NMR (162 MHz, $\left.\mathrm{CDCl}_{3}\right) \delta$ 2.0 (s, 2P, trans-positioned); electron spin resonance (ESR): no signal was observed.

Synthesis of $\left[\mathrm{RuCl}_{2}\left(\mathrm{PPh}_{3}\right)_{2}\left(\mathrm{NH}_{2} \mathrm{Bz}\right)_{2}\right](\mathbf{2})$

$\left[\mathrm{RuCl}_{2}\left(\mathrm{PPh}_{3}\right)_{3}\right](0.47 \mathrm{mmol} ; 0.40 \mathrm{~g})$ was added to a solution of $\mathrm{NH}_{2} \mathrm{Bz}(1.37 \mathrm{mmol} ; 0.15 \mathrm{~g})$ in acetone $(40 \mathrm{~mL})$. The mixture was stirred for $3 \mathrm{~h}$ at RT and the volume was reduced to ca. $5 \mathrm{~mL}$ under flow of argon. A green precipitate was filtered, washed with ethyl ether and dried in vacuum. Yield: $44 \%$; calcd. anal. data for $\mathrm{RuCl}_{2} \mathrm{P}_{2} \mathrm{C}_{50} \mathrm{H}_{48} \mathrm{~N}_{2}: 65.9 \mathrm{C}$, $5.3 \mathrm{H}, 3.1 \% \mathrm{~N}$; found: $63.1 \mathrm{C}, 5.2 \mathrm{H}, 3.1 \% \mathrm{~N}$; IR (CsI) $v_{\max } / \mathrm{cm}^{-1} 3313$ and $3247(\mathrm{w}, \mathrm{N}-\mathrm{H}), 2952$ and 2957 (w, $-\mathrm{CH}_{2}-$ ), 1091 (s, P-C), 316 and 274 (w, Ru-Cl); ${ }^{31} \mathrm{P}$ NMR $\left(162 \mathrm{MHz}, \mathrm{CDCl}_{3}\right) \delta 26.1$ (dd, $1 \mathrm{P},{ }^{2} J_{\mathrm{PP} 7.5 \mathrm{~Hz}}$, cis-positioned), $40.6 \mathrm{ppm}$ (dd, 1P, ${ }^{2} J_{\mathrm{PP} 7.5 \mathrm{~Hz}}$, cis-positioned); ESR: no signal was observed.

Synthesis of $\left[\mathrm{RuCl}_{2}\left(\mathrm{PPh}_{3}\right)_{2}(\mathrm{NHBuPh})\right](\mathbf{3})$

$\left[\mathrm{RuCl}_{2}\left(\mathrm{PPh}_{3}\right)_{3}\right](0.52 \mathrm{mmol} ; 0.50 \mathrm{~g})$ was added to a solution of NHBuPh $(5.2 \mathrm{mmol} ; 0.78 \mathrm{~g})$ in acetone: $\mathrm{CHCl}_{3}$ $(25 \mathrm{~mL})$. The mixture was stirred for $24 \mathrm{~h}$ at RT and the volume was reduced to ca. $5 \mathrm{~mL}$ under flow of argon. A 
dark green compound precipitated with addition of cold petroleum ether, which was filtered, washed with ethyl ether and dried in vacuum. Yield: $40 \%$; calcd. anal. data for $\mathrm{RuCl}_{2} \mathrm{P}_{2} \mathrm{C}_{48} \mathrm{H}_{44} \mathrm{~N}_{2}: 65.3 \mathrm{C}, 5.4 \mathrm{H}, 1.7 \% \mathrm{~N}$; found: $65.7 \mathrm{C}$, $5.4 \mathrm{H}, 1.8 \% \mathrm{~N}$; IR (CsI) $v_{\max } / \mathrm{cm}^{-1} 2956$ and $2929(\mathrm{w}$, $-\mathrm{CH}_{2}-$ ), 2869 (w, $-\mathrm{CH}_{3}$ ), 1092 (s, P-C), 301 (w, Ru-Cl); ${ }^{31} \mathrm{P}$ NMR (162 MHz, $\left.\mathrm{CDCl}_{3}\right) \delta 27.8$ (s, 2P, trans-positioned); ESR: no signal was observed.

\section{Equipment}

Elemental analyses were performed in a PerkinElmer CHN 2400 at the Institute of Chemistry, USP. ESR measurements of the solid sample were carried out at $77 \mathrm{~K}$, using a Bruker ESR 300C (X-band) equipped with a TE102 cavity and HP 52152A frequency counter. FTIR measurements were performed in CsI pellets on a Bomem FTIR MB 102. The NMR $\left({ }^{1} \mathrm{H} ;{ }^{13} \mathrm{C}\left\{{ }^{1} \mathrm{H}\right\} ;{ }^{31} \mathrm{P}\left\{{ }^{1} \mathrm{H}\right\}\right)$ spectra were obtained in $\mathrm{CDCl}_{3}$ at $25.0 \pm 0.1{ }^{\circ} \mathrm{C}$ using a Bruker DRX 400 spectrometer. The obtained chemical shifts were reported in ppm relative to the high frequency of tetramethylsilane (TMS) or $\mathrm{PF}_{6}^{-}$ion. Size-exclusion chromatography (SEC) analyses were carried out in a Shimadzu Prominence LC system equipped with an LC-20AD pump, a DGU-20A5 degasser, a CBM-20A communication module, a CTO-20A oven at $27{ }^{\circ} \mathrm{C}$, and an RID-10A detector connected to three PL gel columns ( $5 \mu \mathrm{m}$ MIXED-C: $30 \mathrm{~cm}, \varnothing=7.5 \mathrm{~mm}$ ). Retention time was calibrated with standard monodispersed polystyrene using HPLC-grade $\mathrm{CHCl}_{3}$ as eluent. PDI is $M_{\mathrm{w}} / M_{\mathrm{n}}$.

\section{Polymerization reactions}

In a typical ROMP experiment, $1.1 \mathrm{mmol}$ of catalyst (1, 2 or 3 ) was dissolved in $2 \mathrm{~mL}$ of $\mathrm{CHCl}_{3}$ and a certain amount of monomer (NBE, NBD or/and DCPD) and $5 \mu \mathrm{L}$ of EDA were added. The solution was stirred for different periods of time at 25 or $50 \pm 1^{\circ} \mathrm{C}$ in a silicon oil bath. At RT, ca. $5 \mathrm{~mL}$ of methanol were added and the polymer was filtered, washed with methanol and dried in a vacuum oven at $27^{\circ} \mathrm{C}$ until a constant weight was achieved. The reported yields are average values from catalytic runs performed at least three times, with maximum $10 \%$ deviation. The isolated polyNBEs were dissolved in $2 \mathrm{~mL}$ of $\mathrm{CHCl}_{3}$ for $\mathrm{SEC}$ measurements.

\section{Results and Discussion}

ROMP with 1 and 2

Complex 1 was active for NBE in the presence of EDA used as carbene source (Table 1). Yields in the range of $20-40 \%$ for $5 \mathrm{~min}$ at $25^{\circ} \mathrm{C}$ were obtained, with the best result at $50{ }^{\circ} \mathrm{C}$ with $5 \mu \mathrm{L}$ of EDA solution $(61 \%)$. A tendency of larger amounts of EDA in reducing the reaction progress was observed, as in earlier studies. ${ }^{27}$ The active metal species was poisoned with excess of EDA, decreasing the propagation rate, or the monomer concentration decreased by cyclopropanation occurrence, as possible reasons to explain that event. ${ }^{33}$ The volume of $5 \mu \mathrm{L}$ was used throughout this work.

Table 1. Dependence of yield, $M_{\mathrm{w}}$ and PDI on the EDA solution volume for ROMP of NBE with 1 for $5 \mathrm{~min}$; $[\mathrm{NBE}] /[\mathrm{Ru}]=5000$

\begin{tabular}{lcccc}
\hline $\begin{array}{l}\text { EDA } \\
\text { solution } / \mu \mathrm{L}\end{array}$ & $\begin{array}{c}\text { Temperature / } \\
{ }^{\circ} \mathrm{C}\end{array}$ & $\begin{array}{c}\text { Yield } / \\
\%\end{array}$ & $\begin{array}{c}M_{\mathrm{w}} / \\
\left(10^{3} \mathrm{~g} \mathrm{~mol}^{-1}\right)\end{array}$ & PDI \\
\hline 3 & 25 & 21 & 95 & 2.36 \\
5 & 25 & 42 & 44 & 2.08 \\
7 & 25 & 22 & 65 & 2.16 \\
10 & 25 & 24 & 70 & 2.47 \\
\hdashline 5 & 50 & 61 & 170 & 2.87 \\
\hline
\end{tabular}

Reactions for $5 \mathrm{~min}$ with $\mathbf{1}$ as a function of [NBE]/[Ru] molar ratio in the range from 1000 to 5000 showed polyNBE yield increased either at 25 or $50^{\circ} \mathrm{C}$ (Figure 2). However, the maximum value was ca. $60 \%$ at $50{ }^{\circ} \mathrm{C}$. Semi-quantitative yields were obtained at $50{ }^{\circ} \mathrm{C}$ when the reaction time was $30 \mathrm{~min}$. Higher yields at $50^{\circ} \mathrm{C}$ were probably obtained because of a faster displacement of a ligand from the six-coordinated species in the induction period, as could be expected. This is necessary to form the metal-carbene species with a coordinated olefin, followed by metallocyclobutane formation. ${ }^{1}$ Thus, the temperature probably facilitated the induction towards initiation, but long periods of reaction time were necessary to obtain better results with $\mathbf{1}$. On the other hand, semi-quantitative yields (ca. 90\%) were already obtained for $5 \mathrm{~min}$ at $50{ }^{\circ} \mathrm{C}$ with complex 2 for different starting [NBE]/[Ru] molar ratios (Table 2).

Decreased results for $[\mathrm{NBE}] /[\mathbf{1}]=10000$ at $25{ }^{\circ} \mathrm{C}$ for 5 min can be associated with the gelation of the medium (Figure 2), which hinders the diffusion of the monomer to the catalyst connected to the polymer chain. However, this was not important at $50{ }^{\circ} \mathrm{C}$, either for 5 or $30 \mathrm{~min}$, with 67 and $97 \%$ of yield, respectively. The $M_{\mathrm{w}}$ values changed from 40 to $88 \times 10^{4} \mathrm{~g} \mathrm{~mol}^{-1}$ as the PDI values decreased from 1.92 to 1.73 (Table S1). In the case of $\mathbf{2}$, good yields were also obtained for molar ratio of $[\mathrm{NBE}] /[\mathrm{Ru}]=10000$, with PDI below 1.9 (Table 2). Considering the catalyst activity in terms of turnover number (TON), it can be observed that the polymer production increases linearly with the monomer load (Table 2). This relationship can 
also be observed in the case of $\mathbf{1}$ at $50{ }^{\circ} \mathrm{C}$ (Table S1). This is an important result, since simple and stable complexes were able to afford ROMP of a large amount of monomer.

Table 2. Dependence of yield, $M_{\mathrm{w}}$ and PDI on the $[\mathrm{NBE}] /[\mathrm{Ru}]$ molar ratio for ROMP with 2 for 5 min at $50{ }^{\circ} \mathrm{C}$

\begin{tabular}{lcccc}
\hline$[\mathrm{NBE}] /[\mathrm{Ru}]$ & Yield $/ \%$ & $\begin{array}{c}M_{\mathrm{w}} / \\
\left(10^{3} \mathrm{~g} \mathrm{~mol}^{-1}\right)\end{array}$ & PDI & TON \\
\hline 1000 & 55 & 210 & 3.04 & 550 \\
3000 & 92 & 83 & 3.28 & 2760 \\
5000 & 93 & 14 & 1.67 & 4650 \\
10000 & 86 & 110 & 1.86 & 8600 \\
\hline
\end{tabular}

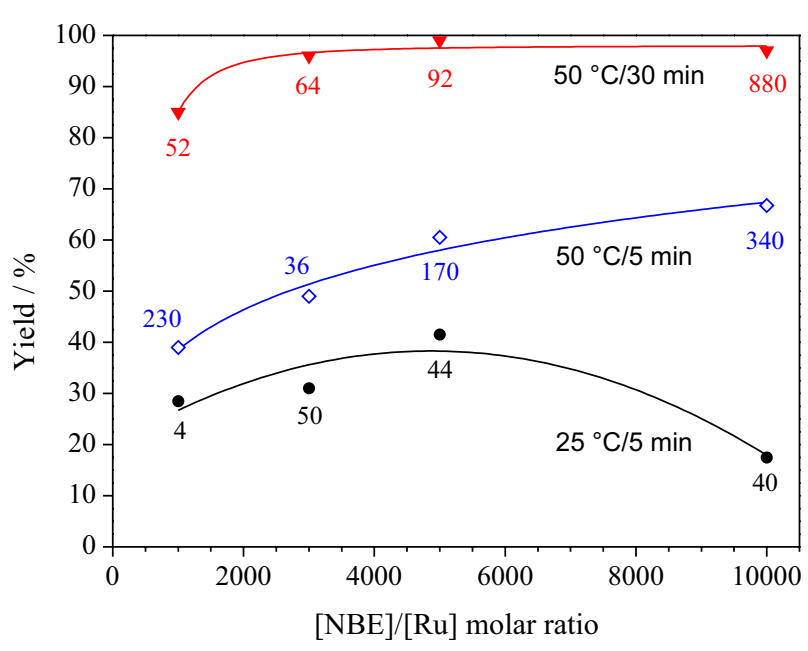

Figure 2. Dependence of yield on the $[\mathrm{NBE}] /[\mathrm{Ru}]$ molar ratio for ROMP of NBE with 1 at 25 or $50{ }^{\circ} \mathrm{C}$, for 5 or $30 \mathrm{~min}$. The numbers are $M_{\mathrm{w}}$ values $\left(10^{3} \mathrm{~g} \mathrm{~mol}^{-1}\right)$.

$M_{\mathrm{w}}$ values with a magnitude order of $10^{4}-10^{5} \mathrm{~g} \mathrm{~mol}^{-1}$ were obtained either with $\mathbf{1}$ or $\mathbf{2}$. PDI values were higher than two for low [NBE] loads, but decreased to values lower than two for higher [NBE] loads (Figure 2; Tables 2 and S1). This can be associated with the induction and initiation reactions, where higher temperatures accelerated these steps affording broad dispersion in the molecular weights, but larger monomer loads resulted in the insertion of more units of monomers in the growing chains, with further time consumption.

The initiator 1 was inactive for NBD at $25{ }^{\circ} \mathrm{C}$ for periods from 5 up to $240 \mathrm{~min}$ and 2 produced only $3-6 \%$ of polyNBD under similar conditions. At $50{ }^{\circ} \mathrm{C}, 13 \%$ with 1 and $29 \%$ with 2 were obtained up to $240 \mathrm{~min}$, with no dependence on time (Table S2). An explanation for the low yields is the possible double coordination of the monomer to the metal complex, which works as a chelating ligand. ${ }^{34}$

\section{ROMP with 3}

High yields (79 to $99 \%$ ) were obtained at $25{ }^{\circ} \mathrm{C}$ for 5 min with $[\mathrm{NBE}] /[\mathrm{Ru}]$ molar ratios in the range of 1000-10000 (Figure 3). This differs from the results with $\mathbf{1}$ and $\mathbf{2}$, where semi-quantitative yields were only obtained at $50{ }^{\circ} \mathrm{C}$ for 30 and $5 \mathrm{~min}$, respectively.

$M_{\mathrm{w}}$ values with an order of magnitude of $10^{4} \mathrm{~g} \mathrm{~mol}^{-1}$ and narrower distributions resulted in high NBE loads (Figure 3). $M_{\mathrm{w}}$ increased by one order of magnitude for a run with $[\mathrm{NBE}] /[\mathrm{Ru}]$ molar ratio of 10000 in $4 \mathrm{~mL}$ of solvent (from $10^{4}$ to $10^{5} \mathrm{~g} \mathrm{~mol}^{-1}$ ). In this case, the yield decreased ca. $10 \%$, but the PDI improved from 1.96 to 1.60 . The increase in the $M_{\mathrm{w}}$ value probably occurred because of the better dissolution of the growing polymer in larger volume, providing the accessibility of the monomer to the metal center. Rapid gelation of the solution occurred with $2 \mathrm{~mL}$ of solvent preventing short chains from increasing.

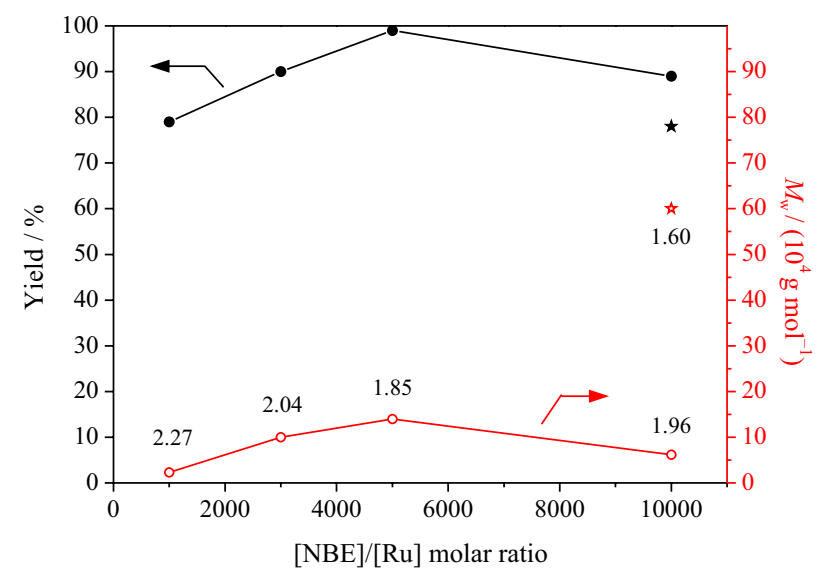

Figure 3. Dependence of yield (solid circles) and $M_{\mathrm{w}}$ (open circles) on the [NBE]/[Ru] molar ratio for ROMP of NBE with 3 in $2 \mathrm{~mL}$ of solvent, at $25^{\circ} \mathrm{C}$ for $5 \mathrm{~min}$. The stars indicate the results with $4 \mathrm{~mL}$ of solvent. The numbers are PDI values.

Syntheses of polyNBD were sensitive to temperature and period of reaction time, with $90 \%$ yield at $50{ }^{\circ} \mathrm{C}$ for 30 min (Table 3; entries 2-4). The yield was also high for $5 \mathrm{~min}$ at $50{ }^{\circ} \mathrm{C}(78 \%)$, but it differed from the quantitative results for polyNBE at $25^{\circ} \mathrm{C}$ for $5 \mathrm{~min}$ (Table 3 ; entry 1). This was probably because the coordination of the two cyclic olefins in the NBD molecule, which could also explain the low yields with DCPD (Table 3; entries 5-6). Higher temperatures prevented the stabilization of the catalyst through double coordination of NBD, ${ }^{31}$ with loss of yield in the case of DCPD (26-21\% yield at $50{ }^{\circ} \mathrm{C}$ for 60-120 min, Table 3; entries 5-6).

PolyDCPD was not produced at $25{ }^{\circ} \mathrm{C}$ for $60 \mathrm{~min}$. PolyNBD and polyDCPD were insoluble in $\mathrm{CHCl}_{3}$ owing to crosslinking occurrence. 
Table 3. Dependence of the yield on the temperature and reaction time for ROMP with $\mathbf{3}$

\begin{tabular}{|c|c|c|c|c|}
\hline entry & Monomer $^{\mathrm{a}}$ & Temperature $/{ }^{\circ} \mathrm{C}$ & time / min & Yield / \% \\
\hline 1 & $\mathrm{NBE}$ & 25 & 5 & 99 \\
\hline 2 & NBD & 25 & 30 & 44 \\
\hline 3 & NBD & 50 & 5 & 78 \\
\hline 4 & NBD & 50 & 30 & 90 \\
\hline 5 & DCPD & 50 & 60 & 26 \\
\hline 6 & DCPD & 50 & 120 & 21 \\
\hline 7 & NBE/DCPD ${ }^{\mathrm{b}}$ & 50 & 60 & 35 \\
\hline 8 & NBD/DCPD ${ }^{\mathrm{b}}$ & 50 & 60 & 31 \\
\hline
\end{tabular}

Catalytic runs with NBE and NDB with different feed ratios of $[\mathrm{NBE}] /[\mathrm{NBD}]$ and $[\mathrm{NBD}] /[\mathrm{NBE}]$ were carried out, where a fixed [monomer]/[Ru] molar ratio was blended with increasing [comonomer]/[Ru] (Table 4). In the case of fixed NBE load, a linear decrease of semi-quantitative yield to $49 \%$ was observed when the NBD load increased up to feed ratio of $[\mathrm{NBE}] /[\mathrm{NBD}]=1$ (Figure 4 ). On the other hand, increasing the NBE load in solutions with fixed amount of NBD greatly reduced the yield compared with that of the homopolymerization for any feed ratio of [NBD]/[NBE] (Table 4). In the latter case, an ascendant linear trend line can be observed with the rising NBE load (Figure 4).

The results are consistent with the production of copolymers, considering that blended polymers will be isolated with yields in correlation with the production of the homopolymers where the reactivities of $\mathbf{3}$ with NBE and NBD are very high.

Therefore, the profiles can be associated with the reactivity ratios of the monomers to produce the copolymer, defining how much NBE and NBD was inserted in polyNBE $\left(r_{1}\right)$, and how much NBD and NBE was inserted in polyNBD $\left(r_{2}\right)$, considering the feed ratios [NBE]/[NBD]

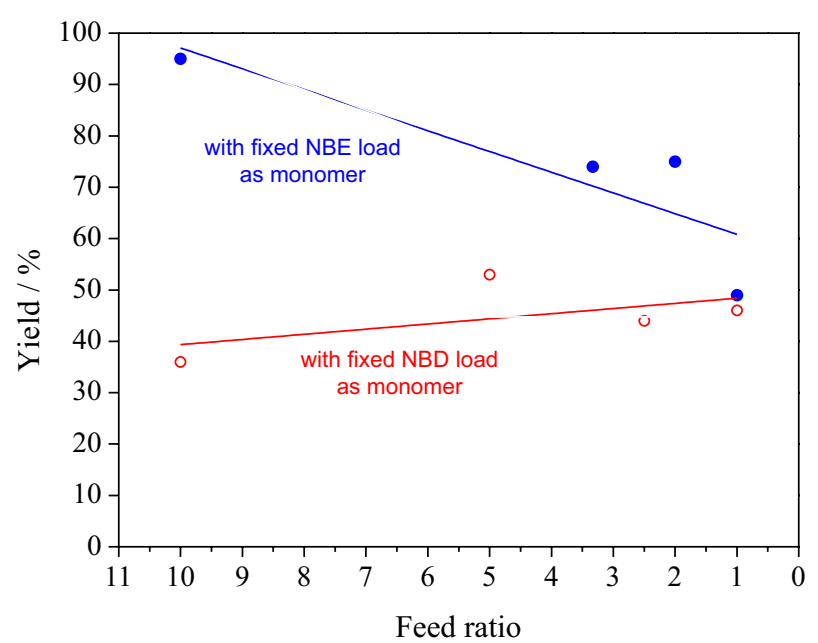

Figure 4. Dependence of yield on the [monomer]/[comonomer] feed ratio for ROMCP of NBE and NBD with $\mathbf{3}$, at $50{ }^{\circ} \mathrm{C}$ for $30 \mathrm{~min}$.

and $[\mathrm{NBD}] /[\mathrm{NBE}]{ }^{35,36}$ The following equation represents the reactivity ratios $(r)$ described in terms of the rate constants $(k)$ for the propagation steps ${ }^{35}$ where $k_{\mathrm{NBE} / \mathrm{NBE}}$ is polyNBE inserting NBE, $k_{\mathrm{NBE} / \mathrm{NBD}}$ is polyNBE inserting $\mathrm{NBD}, k_{\mathrm{NBD} / \mathrm{NBD}}$ is polyNBD inserting NBD, and $k_{\mathrm{NBD} / \mathrm{NBE}}$ is polyNBD inserting NBE:

$r_{1}=\frac{k_{N B E / N B E}}{k_{N B E / N B D}} ; r_{2}=\frac{k_{N B D / N B D}}{k_{N N B D / N B E}}$

Unfortunately, the chemical compositions of the isolated materials were not determined due to their very low solubility in $\mathrm{CHCl}_{3}$ to take NMR measurements. However, a few suggestions with respect to reactivity ratios can be evaluated from the yield results.

First, given that the presence of comonomers decreased the yields relative to that of the homopolymerizations, it is possible to expect values higher than 1 for both $r_{1}$ and $r_{2}$. This occurs because the yields for homopolymerizations

Table 4. Dependence of yield on the NBE-NBD composition for ROMCP with $\mathbf{3}$ for $30 \mathrm{~min}$ at $50{ }^{\circ} \mathrm{C}$; [monomer]/[Ru] $=5000$

\begin{tabular}{|c|c|c|c|c|}
\hline Monomer $^{\mathrm{a}}$ & {$[$ Comonomer]/[Ru] } & {$[\text { Monomer }]_{\text {total }} /[\mathrm{Ru}]^{\mathrm{b}}$} & Feed ratio $^{c}$ & Yield / \% \\
\hline \multirow{5}{*}{ NBE } & 0 & 5000 & - & 99 \\
\hline & 500 & 5500 & 10 & 95 \\
\hline & 1500 & 6500 & 3.3 & 74 \\
\hline & 2500 & 7500 & 2 & 75 \\
\hline & 5000 & 10000 & 1 & 49 \\
\hline \multirow[t]{5}{*}{ NBD } & 0 & 5000 & - & 90 \\
\hline & 500 & 5500 & 10 & 36 \\
\hline & 1000 & 6000 & 5 & 53 \\
\hline & 2000 & 7000 & 2.5 & 44 \\
\hline & 5000 & 10000 & 1 & 46 \\
\hline
\end{tabular}

a $([$ monomer $] /[\mathrm{Ru}]=5000) ;{ }^{\mathrm{b}}[\text { Monomer }]_{\text {total }}=[$ monomer $]+[$ comonomer $] ;$ c feed ratio $=[$ monomer $] /[$ comonomer $]$. 
were much better than those for copolymerization, indicating that $k_{\mathrm{NBE} / \mathrm{NBE}}>k_{\mathrm{NBE} / \mathrm{NBD}}$ and $k_{\mathrm{NBD} / \mathrm{NBD}}>k_{\mathrm{NBD} / \mathrm{NBE}}$, where insertion of NBE in polyNBE would be more effective than insertion of NBD $\left(r_{1}>1\right)$, and insertion of NBD in polyNBD would be more effective than insertion of $\operatorname{NBE}\left(r_{2}>1\right)$. Furthermore, $k_{\mathrm{NBE} / \mathrm{NBE}}>>k_{\mathrm{NBD} / \mathrm{NBD}}$ is expected, considering that quantitative polyNBE yield was obtained at $25^{\circ} \mathrm{C}$ for $5 \mathrm{~min}$, whereas semi-quantitative yield for polyNBD was only obtained at $50{ }^{\circ} \mathrm{C}$ for $30 \mathrm{~min}$ (Table 3; entries 1 and 4). Finally, $k_{\mathrm{NBE} / \mathrm{NBD}}<<k_{\mathrm{NBD} / \mathrm{NBE}}$ is also expected, taking into account that the abrupt drop in the yield for copolymerization of NBD varying NBE is not observed in copolymerization of NBE varying NBD (Table 4). Thus, from these remarks, $r_{1}$ is expected to be higher than $r_{2}$, with occurrence of a greater reactivity with NBE in both cases. It is clearly observed that increasing NBE load in the mixtures, when increasing [NBE]/[NBD] or decreasing [NBD]/[NBE], increases the yields (Figure 4). Under this circumstance, it is important to note the match in the yield results for equimolar loads of monomers $([\mathrm{NBE}] /[\mathrm{NBD}]=[\mathrm{NBD}] /[\mathrm{NBE}]=1)$.

Yields from copolymerizations NBE-DCPD and NBD-DCPD were ca. 35-31\% with equimolar monomer loads at $50{ }^{\circ} \mathrm{C}$ for $60 \mathrm{~min}$ (Table 3 ; entries 7 and 8). Double coordination of DCPD to the metal center, as already discussed, could explain the low yields. ${ }^{34}$

\section{Comparison of the reactivity with complexes 1, 2 and 3}

Yields for polyNBE and polyNBD were dependent on the reaction time, [monomer]/[Ru] molar ratio and temperature with different yield patterns.

At $25^{\circ} \mathrm{C}$ for $5 \mathrm{~min}$, complexes $\mathbf{1}$ and $\mathbf{2}$ produced less than $30 \%$ of polyNBE, whereas complex $\mathbf{3}$ produced quantitative yield. At $50{ }^{\circ} \mathrm{C}$ for $5 \mathrm{~min}$, complex 1 showed moderate yields (ca. 60\%), while complex 2 showed quantitative yields. Complex 1 only showed quantitative yields at $50{ }^{\circ} \mathrm{C}$ for $30 \mathrm{~min}$.

Yields for polyNBD were lower for complexes $\mathbf{1}$ and 2 regardless of the reaction time and temperature. Complex 3 produced quantitative yield for $30 \mathrm{~min}$ and semi-quantitative for $5 \mathrm{~min}$, at $50{ }^{\circ} \mathrm{C}$.

Considering the studied conditions, the complexes presented good reactivity for ROMP with variation in the yields, which can be associated with both the structure of the complexes and the characteristics of the amine ligands combined with $\mathrm{PPh}_{3}$.

Complexes 1 and $\mathbf{2}$ were six-coordinated with two amines while complex $\mathbf{3}$ was five-coordinated with only one amine molecule, considering the analytical data. The ESR spectra were silent, suggesting that the ruthenium centers presented $2+$ oxidation states with low spin $\mathrm{d}^{6}$ electronic configurations. Elementary analyses indicated complexes with two phosphines and two chloride ions. Typical vibration bands in the FTIR spectra confirmed the presence of chlorides, amines and phosphines in the complexes. The ${ }^{31} \mathrm{P}$ NMR spectrum of $\mathbf{1}$ in $\mathrm{CDCl}_{3}$ at $25{ }^{\circ} \mathrm{C}$ showed only one singlet at $2.0 \mathrm{ppm}$, suggestive of trans-positioned $\mathrm{PPh}_{3}$ molecules (Figure S1). Thus, a $t t t-\left[\mathrm{RuCl}_{2}(\mathrm{PPh} 3)_{2}\left(\mathrm{NH}_{2} \mathrm{Ph}\right)_{2}\right]$ conformation could be proposed (Figure 5), considering that only one sharp vibration peak in the region of $v(\mathrm{Ru}-\mathrm{Cl})$ stretching mode was observed. ${ }^{29,30}$ The ${ }^{31} \mathrm{P}$ NMR spectrum did not change for $12 \mathrm{~h}$. The ${ }^{31} \mathrm{P}$ NMR spectrum of complex 2 showed a double doublet typical of a six-coordinated complex containing unequivalent cis-positioned P-atoms (26.1 and $40.6 \mathrm{ppm} ;{ }^{2} J_{\mathrm{PP}} 7.5 \mathrm{~Hz}$; Figure S2). In this case, a $c c c-\left[\mathrm{RuCl}_{2}(\mathrm{PPh} 3)_{2}\left(\mathrm{NH}_{2} \mathrm{Bz}\right)_{2}\right]$ conformation could be considered (Figure 5), in agreement with two $v(\mathrm{Ru}-\mathrm{Cl})$ bands. ${ }^{29,30}$ In addition, observed signals at $40.4 \mathrm{ppm}$ can be associated with five-coordinated complexes upon dissociation of amine or phosphine ligands, which can undergo dimerization $\left(50.6 \mathrm{ppm} ;{ }^{2} J_{\mathrm{PP}} 28.5 \mathrm{~Hz}\right)$.
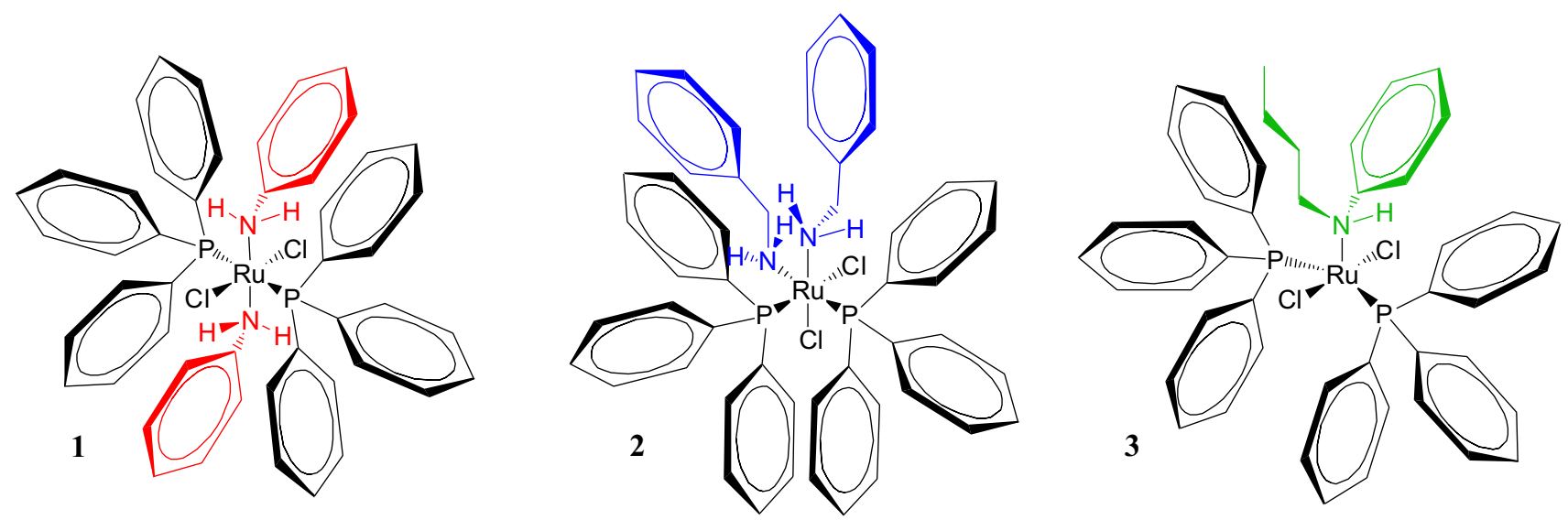

Figure 5. Illustration of the possible structures of complexes 1, 2 and $\mathbf{3}$. 
The ${ }^{31} \mathrm{P}$ NMR spectrum of $\mathbf{3}$ showed a singlet at $27.8 \mathrm{ppm}$ (Figure S3), suggesting that the two $\mathrm{PPh}_{3}$ ligands were equivalently located in the complex. Correlating this result with the FTIR spectrum, where only one $v(\mathrm{Ru}-\mathrm{Cl})$ band was observed that suggested that the two chloride ions were trans-positioned, ${ }^{29,30}$ a square pyramidal geometry can be defined for the complex with NHBuPh at the apical position (Figure 5). The spectrum did not show the appearance of other signals as a function of time. It is important to observe the absence of signals associated with binuclear species in the solution, as promptly occurred when dissolving the fivecoordinated $\left[\mathrm{RuCl}_{2}\left(\mathrm{PPh}_{3}\right)_{3}\right]$ complex in $\mathrm{CHCl}_{3} \cdot{ }^{29} \mathrm{In}$ the latter case, the displacement of one $\mathrm{PPh}_{3}$ molecule occurred owing to the large steric hindrance around the coordination sphere. On the other hand, the presence of the amine NHBuPh in $\mathbf{3}$ tuned the steric hindrance around the metal center without occurrence of departure of ligands. The NMR spectrum of 3 remained the same for $12 \mathrm{~h}$ at RT.

From the supposed geometric structures, it can also be concluded that complex $\mathbf{1}$ did not either undergo dimerization process or geometric rearrangement when in solution, as a function of time. Both complexes $\mathbf{1}$ and $\mathbf{3}$ showed stability at RT for $12 \mathrm{~h}$, contrary to complex $\mathbf{2}$, where the ${ }^{31} \mathrm{P}$ NMR spectrum showed evidence of other species in solution. In the case of $\mathbf{1}$ and $\mathbf{3}$, restriction of $\mathrm{PPh}_{3}$ departure occurs by absence of steric hindrance on the metal coordination sphere where the phosphines are transpositioned to each other. Complex $\mathbf{1}$ is six-coordinated, but the amines present low cone angle. In the case of $\mathbf{3}$, the amine presents a higher cone angle and the complex is five-coordinated. In both cases, the low $\sigma$-donor character of the amines is inefficient to disturb the stability of the complexes. Furthermore, the nonexistence of a geometrical rearrangement in the five-coordinated complex $\mathbf{3}$ could also be attributed to an adjusted steric hindrance in the coordination metal sphere, provided by the butyl group in the amine, in spite of the low $\sigma$-donor character as in $\mathrm{NH}_{2} \mathrm{Ph}$. In the case of $\mathbf{2}$, the six-coordinated complex lost $\mathrm{PPh}_{3}$ because the $c c c$ geometric arrangement provoked a steric hindrance in the coordination sphere, in addition to the high $\sigma$-donor character of the $\mathrm{NH}_{2} \mathrm{Bz}$ raising the electronic density in the $\left\{\mathrm{Cl}_{2} \mathrm{Ru}(\mathrm{II})\right\}$ moiety.

Therefore, if the complexes $\mathbf{1}$ and $\mathbf{2}$ are six-coordinated (Figure 5), where the amines $\mathrm{NH}_{2} \mathrm{Ph}\left(\theta=111^{\circ}\right)$ and $\mathrm{NH}_{2} \mathrm{Bz}$ $\left(\theta=106^{\circ}\right)$ present almost the same cone angles without providing a significant steric hindrance, an increase in temperature is necessary for better reactivity. However, an increase in the reaction time is not necessary in the case of $\mathbf{2}$, as in the case of $\mathbf{1}$, since $\mathrm{NH}_{2} \mathrm{Bz}$ is more basic than $\mathrm{NH}_{2} \mathrm{Ph}$, besides the fact that the $\mathrm{NH}_{2} \mathrm{Bz}$ molecules can be cis-positioned. In addition, in the case of $\mathbf{1}$, a slow propagation rate can be expected where the reaction time was cooperative with the temperature to achieve better results. This can be concluded taking into account a weak $\sigma$-donor effect from $\mathrm{NH}_{2} \mathrm{Ph}$ to forward monomer activation via a synergism amine $\rightarrow \mathrm{Ru} \rightarrow$ monomer and a low steric hindrance around the metal center to accelerate the replacement of ligands. Difference in the inertness between $\mathbf{1}$ and $\mathbf{2}$ can be correlated with the NMR spectra, where the spectrum of $\mathbf{1}$ did not show changes for hours and the spectrum of $\mathbf{2}$ changed over time. As semi-quantitative yields with $\mathbf{1}$ were only achieved for $30 \mathrm{~min}$ at $50{ }^{\circ} \mathrm{C}$, the difference in reactivity can be associated with the better synergism amine $\rightarrow \mathrm{Ru} \rightarrow$ monomer in $\mathbf{2}$, owing to the higher $\sigma$-donor character of $\mathrm{NH}_{2} \mathrm{Bz}\left(\mathrm{pK}_{\mathrm{a}}=9.4\right)$, as the cone angles are similar (Figure 1).

The temperature increase favors the formation of the metal-carbene moiety and the coordination of the olefin from the discoordination of ligands. In the case of complex $3, \mathrm{NHBuPh}$ presents a $\sigma$-donor character similar to that of $\mathrm{NH}_{2} \mathrm{Ph}$, but a higher cone angle (expected $\theta>\theta_{\text {NHEtPh }}=126^{\circ}$ ), which enabled a five-coordinated complex (Figure 5). The higher steric hindrance in $\mathbf{3}$ provided better results in ROMP with no increase in the reaction time or temperature. Therefore, the nature of the amines and geometric arrangements seems to explain the obtained ROMP results.

\section{Data for ${ }^{13} \mathrm{C}$ NMR spectra of polyNBE}

Analyses of the ${ }^{13} \mathrm{C}$ NMR spectra from polyNBE synthesized with complexes $\mathbf{1}, \mathbf{2}$ and $\mathbf{3}$ showed that the fractions of the cis structures $\left(\sigma_{\mathrm{c}}\right)$ were between 0.4 and 0.5 , considering the $\mathrm{C}^{1,4}$ peak areas (Figure S4; Table S3).

\section{Conclusions}

Three $\mathrm{Ru}$ (II) complexes of the type $\left[\mathrm{RuCl}_{2}\left(\mathrm{PPh}_{3}\right)_{2}(\text { amine })_{\mathrm{x}}\right]$, with amine $=\mathrm{NH}_{2} \mathrm{Ph}(\mathbf{1})$ or $\mathrm{NH}_{2} \mathrm{Bz}(\mathbf{2})$, for $\mathrm{x}=2$, and amine $=\operatorname{NHBuPh}(\mathbf{3})$ for $\mathrm{x}=1$, have been synthesized. The complexes were tested in the ROMP of NBE, NBD, DCPD and copolymerizations of NBE-NBD, NBE-DCPD and NBD-DCPD, in the presence of EDA. In the series, complex $\mathbf{3}$ is the most active, probably because there is more steric hindrance due to the number and the bulkiness of the ligands, even with a lower $\sigma$-donor character.

Concluding, simple, inexpensive and easy-to-handle amines combined with $\mathrm{PPh}_{3}$ produced active complexes to prepare polymers and copolymers via ROMP, where the steric hindrance in the initiator is very important for its reactivity. Nowadays, Grubbs-type complexes are very important for the continuous advancement in olefin 
metathesis. However, the presented complexes can be alternative non-Grubbs-type initiators for ROMP, as other suggestions from the literature..$^{37-39}$

\section{Supplementary Information}

Supplementary information is available free of charge at http://jbcs.sbq.org.br as PDF file.

\section{Acknowledgements}

The authors are grateful to FAPESP (Proc. 06/57577-4), CAPES, and CNPq for financial support. The $400 \mathrm{MHz}-\mathrm{NMR}$ analyses were performed at the Departamento de Química, Universidade Federal São Carlos, São Carlos-SP, Brazil. This article is dedicated to the memory of Prof Roberto Fernando de Souza. We have always admired Prof Roberto for his concern in the development of a good research, as well as his dedication to the development of catalysis in Brazil.

\section{References}

1. Ivin, K. J.; Mol, J. C.; Olefin Metathesis and Metathesis Polymerization; Academic Press: New York, 1997.

2. Grubbs, R. H.; Handbook of Metathesis, vol. 3; Wiley-VCH: Weinheim, 2003.

3. Bielawski, C. W.; Grubbs, R. H.; Prog. Polym. Sci. 2007, 32, 1.

4. Slugovc, C.; Macromol. Rapid Commun. 2004, 25, 1283.

5. Leitgeb, A.; Wappel, J.; Slugovc, C.; Polymer 2010, 51, 2927.

6. Buchmeiser, M. R.; Chem. Rev. 2000, 100, 1565.

7. Deraedt, C.; d'Halluin, M.; Astruc, D.; Eur. J. Inorg. Chem. 2013, 4881.

8. Ding, L.; Yang, G.; Xie, M.; Gao, D.; Yub, J.; Zhang, Y.; Polymer 2012, 53, 333.

9. Fogg, D. E.; Amoroso, D.; Drouin, S. D.; Snelgrove, J.; Conrad, J.; Zamanian, F.; J. Mol. Catal. A: Chem. 2002, 190, 177.

10. Grubbs, R. H.; Tetrahedron 2004, 60, 7117.

11. Nayab, S.; Park, W.; Wooa, H. Y.; Sung, I. K.; Hwang, W. S.; Lee, H.; Polyhedron 2012, 42, 102.

12. Nakayama, Y.; Tanimoto, M.; Shiono, T.; Macromol. Rapid Commun. 2007, 28, 646.

13. Vougioukalakis, G. C.; Grubbs, R. H.; Chem. Rev. 2010, 110, 1746.

14. Frenzel, U.; Nuyken, O.; J. Polym. Sci., Part A: Polym. Chem. 2002, 40, 2895.

15. Schrock, R. R.; Hoveyda, A. H.; Angew. Chem., Int. Ed. 2003, 42, 4592.

16. Olszewski, T. K.; Bieniek, M.; Skowerski, K.; Grela, K.; Synlett 2013, 24, 903.
17. Opstal, T.; Verpoort, F.; J. Mol. Catal. A: Chem. 2003, $200,49$.

18. Allaert, B.; Dieltiens, N.; Ledoux, N.; Vercaemst, C.; van der Voort, P.; Stevens, C. V.; Linden, A.; Verpoort, F.; J. Mol. Catal. A: Chem. 2006, 260, 221.

19. Cherumuttathu, H. S.; Nobuaki, K.; Organometallics 2004, 23, 76.

20. Scholl, M.; Ding, S.; Lee, C. W.; Grubbs, R. H.; Org. Lett. 1999, $1,953$.

21. Keitz, B. K.; Fedorov, A.; Grubbs, R. H.; J. Am. Chem. Soc. 2012, 134, 2040.

22. Hong, S. H.; Grubbs, R. H.; J. Am. Chem. Soc. 2006, 128, 3508.

23. Samec, J. S. M.; Keitz, B. K.; Grubbs, R. H.; J. Organomet. Chem. 2010, 695, 1831.

24. Vidavsky, Y.; Anaby, A.; Lemcoff, N. G.; Dalton Trans. 2012 , $41,32$.

25. Tolman, C. A.; J. Am. Chem. Soc. 1970, 92, 2956.

26. Hall Jr., H. K.; J. Am. Chem. Soc. 1957, 79, 5441.

27. Matos, J. M. E.; Lima-Neto, B. S.; J. Mol. Catal. A: Chem. 2004, $222,81$.

28. Matos, J. M. E.; Lima-Neto, B. S.; J. Mol. Catal. A: Chem. 2006, 259, 286.

29. Sá, J. L. S.; Vieira, L. H.; Nascimento, E. S. P.; Lima-Neto, B. S.; Appl. Catal., A 2010, 374, 194.

30. Carvalho Jr., V. P.; Ferraz, C. P.; Lima-Neto, B. S.; J. Mol. Catal. A: Chem. 2010, 333, 46.

31. Carvalho Jr., V. P.; Ferraz, C. P.; Lima-Neto, B. S.; Eur. Polym. J. 2012, 48, 341 .

32. Armit, P. W.; Boyd, A. S. F.; Stepheson, T. A.; J. Chem. Soc., Dalton Trans. 1975, 1663.

33. Moody, C. J.; Whitham, G. H.; Reactive Intermediates; Oxford University Press: New York, 1995, pp. 26-50.

34. Sá, J. L. S.; Nascimento, E. S. P.; Fonseca, L. R.; Lima-Neto, B. S.; J. Appl. Polym. Sci. 2013, 127, 3578.

35. Odian, G.; Principles of Polymer, $4^{\text {th }}$ ed.; John Wiley \& Sons: Hoboken, 2004.

36. Young, R. J.; Lovell, P. A.; Introduction to Polymers, $3^{\text {rd }}$ ed.; CRC Press: Boca Raton, 2011.

37. Mothes, E.; Sentets, S.; Luquin, M. A.; Mathieu, R.; Lugan, N.; Lavigne, G.; Organometallics 2008, 27, 1193.

38. Sauvage, X.; Borguet, Y.; Noels, A. F.; Delaude, L.; Demonceau, A.; Adv. Synth. Catal. 2007, 349, 255.

39. Chen, J.; Chen, X.; Zhu, J.; J. Mol. Catal. A: Chem. 2014, 394, 198.

Submitted: August 15, 2014

Published online: November 11, 2014

FAPESP has sponsored the publication of this article. 